\title{
BATIK TULIS PADANG LAMUN (PADANG LAMUN SEBAGAI SUMBER IDE PERANCANGAN BATIK TULIS UNTUK SELENDANG SUTRA)
}

\author{
Andina Febrasari ${ }^{1}$ (andina.fb95@gmail.com, Program Studi Kriya Tekstil, FSRD, Universitas Sebelas Maret) \\ Felix Ari Dartono² (felixari@staff.uns.ac.id, Program Studi Kriya Tekstil, FSRD, Universitas Sebelas Maret) \\ Ratna Endah Santoso ${ }^{3}$ (cezaraesa@gmail.com, Program Studi Kriya Tekstil, FSRD, Universitas Sebelas Maret)
}

\begin{abstract}
Seagrass bads is a variety of flora that lives on the sea coast. The objective of this project is to produce a new visual alternative for silk batik scarfs by visualizing Seagrasses bads which live under water; its illusion of motion, dimensions, and biodiversity. This research use design method consist of exploration process, extraction, and termination are described in four operational steps i.e. analysis, concept, visualization, and prototypes. The design is directed at new creative batik for premium products. The result was a silk batik scarfs made by Lorodan batik technique which was able to produce illusory effects and layered images which would offer a new visual sensation, differentiation, and novelty.
\end{abstract}

Keywords: Seagrass Bads, batik tulis, silk scarf

ABSTRAK

Padang Lamun merupakan keanekaragaman flora yang hidup di pesisir laut. Tujuan penelitian ini adalah memberikan alternatif visual baru desain batik tulis untuk selendang sutra dengan mengolah visual Padang Lamun yang hidup terendam air, ilusi gerak, dimensi, dan ragam biota. Penelitian ini menggunakan pendekatan desain yang terdiri atas proses eksplorasi, ekstraksi, dan titik terminasi yang dijabarkan dalam empat langkah operasional, yakni analisis, konsep, visualisasi, dan tes produk. Desain diarahkan pada batik kreasi baru untuk produk premium. Hasilnya berupa desain selendang sutra menggunakan teknik batik tulis Lorodan yang mampu menghasilkan efek ilusi dan bayangan, sehingga memberikan sensasi visual baru, diferensiasi, dan kebaharuan.

Kata Kunci : Padang Lamun, batik tulis, selendang sutra 


\section{PENDAHULUAN}

Batik di Indonesia pada awalnya dikenal dengan gaya klasik menggunakan motif mengikuti aturan serta fungsi tertentu. Saat ini keragaman motif batik semakin luas dengan munculnya batik kreasi baru. Pengembangan desain batik kreasi baru merupakan batik yang berkembang dari segi gaya, motif, serta pengembangan teknikteknik batik. Salah satu yang menjadi ciri batik kreasi baru, yaitu motif dan isen tergantung pada si pencipta dan tidak terikat dengan tradisi tertentu (Susanto, 1980: 287). Menurut Biranul Anas, batik kreasi baru mengandung kebaharuan, memiliki karakter khusus (unik), dan sesuai dengan perkembangan zaman yang ditandai oleh kesementaraan atau trend, sehingga batik kreasi baru mampu menjawab tuntutan zaman (Anas, 1997: 240-246).

Sejalan dengan berkembangnya batik kreasi baru memicu munculnya visual-visual baru pada batik yang memberikan tempat pada garapan personal yang bermula dari ketertarikan personal terhadap objek tertentu salah satunya keanekaragam flora yang diminati oleh kaum wanita. Motif yang sering digunakan biasanya menggambarkan tumbuhan-tumbuhan darat dan hanya sedikit yang berupa tumbuhan laut.

Tulisan ini bertujuan menawarkan Padang Lamun sebagai sumber ide dalam pengolahan motif batik. Padang Lamun merupakan salah satu habitat yang ada di sebagian besar pesisir pulau di Indonesia salah satunya Kepulauan Karimunjawa. Tanaman Lamun yang mengisi habitat tersebut termasuk tanaman yang dilindungi. Hamparan tanaman Lamun atau Padang Lamun (seagrass bads) memiliki keunikan tersendiri, yakni dapat hidup di perairan dangkal dan berpasir. Selain itu, Padang Lamun penting dalam menunjang kehidupan dan perkembangan jasad hidup di laut dangkal, di antaranya sebagai produsen primer dan habitat biota (Nugraha, 2015: 97).

Visual Padang Lamun berupa sekumpulan tumbuhan Lamun, memiliki daun memanjang seperti pita yang bergerak mengikuti gelombang air, dan hidup terbenam di dalam air, sehingga menghasilkan ilusi gerak dan dimensi yang menarik untuk diolah dalam batik. Padang Lamun dapat diangkat sebagai alternatif motif flora selain tumbuhan yang ada di darat. Pengolahan motif Padang Lamun dengan variasi gaya dapat menambah nilai estetis serta keunikan motif.

Visual Batik Padang Lamun dapat dicapai mengunakan teknik pengerjaan yang tepat. Teknik batik tulis Lorodan digunakan untuk menghasilkan warna tambahan akibat dari pertemuan warna, sehingga memunculkan efek bayangan yang merepresentasikan Padang Lamun yang berada di dalam air. Batik Padang Lamun ini diterapkan pada kain sutra agar mendukung karakter tumbuhan lamun yang luwes dan disesuaikan dengan fungsinya.

Desain diarahkan dalam produk premium selendang batik tulis, mengingat selendang merupakan pelengkap busana masa lampau yang tetap digemari oleh wanita hingga saat ini. Wanita dewasa dalam kelas sosial tertentu menggunakan produk pelengkap busana ini dengan kualitas yang tinggi demi memperlihatkan eksistensinya. Hasil pengolahan visual Padang Lamun, inovasi teknik batik tulis Lorodan, dan penggunaan bahan sutra saling mendukung satu sama lain. Produk ini memiliki nilai kebaharuan dan diferensiasi dengan tampilan visual baru pada batik tulis yang memunculkan ilusi gerak dengan teknik batik Lorodan. 


\section{Padang Lamun}

Lamun adalah tumbuhan berbunga yang tumbuh di perairan dangkal dan estuari (Kawaroe, 2009: 2). Lamun sebagai tumbuhan sejati, secara struktural dan fungsional mirip dengan rumput daratan dengan ciri-ciri daun, batang, akar dan struktur alat reproduksinya (bunga dan daun) (Kuslani, 2014: 105). Kebanyakan spesies Lamun mempunyai ciri secara umum yang hampir serupa, yaitu mempunyai daun-daun panjang, tipis, dan mirip pita (Nybakken, 1992: 190).

Hamparan Lamun di laut dangkal atau dapat disebut juga dengan Padang Lamun (Seagrass Bads) terletak di daerah pesisir dan tumbuh di perairan dangkal yang agak berpasir. Sering pula dijumpai di terumbu karang. Tumbuhan ini telah menyesuaikan diri untuk hidup terbenam di dalam air laut. Beberapa biota yang hidup di Padang Lamun, seperti krustasea, moluska, cacing, teripang, dan ikan. Setiap jenis ikan mempunyai atau memiliki habitat yang berbeda-beda, ada yang dari larva hingga dewasa hidup di Padang Lamun, ada yang dari larva hingga juvenile (remaja) hidup di Lamun kemudian dewasa ke perairan lepas. Fungsi dari Padang Lamun yaitu sebagai habitat dan makanan serta tempat berlindung organisme laut lainnya.

Terdapat empat jenis spesies Lamun yang ditemukan di Taman Nasional Karimunjawa, yaitu Thalassia hemprichii, Halophilla ovalis, Enhalus acoroides, dan Cymodocea rotundata. Thalassia hemprichii merupakan tumbuhan Lamun yang paling dominan tumbuh di Kepulauan Karimunjawa memiliki daun lurus hingga sedikit melengkung seperti sabit yang tebal. Helaian daunnya pipih dan lebar. Bagian pangkal daun agak menyempit. Daun bercabang dua tidak terpisah, berbentuk pita, dan bertepi rata dengan ujung membulat. Panjang daun hingga $40 \mathrm{~cm}$ tetapi biasanya lebih pendek.

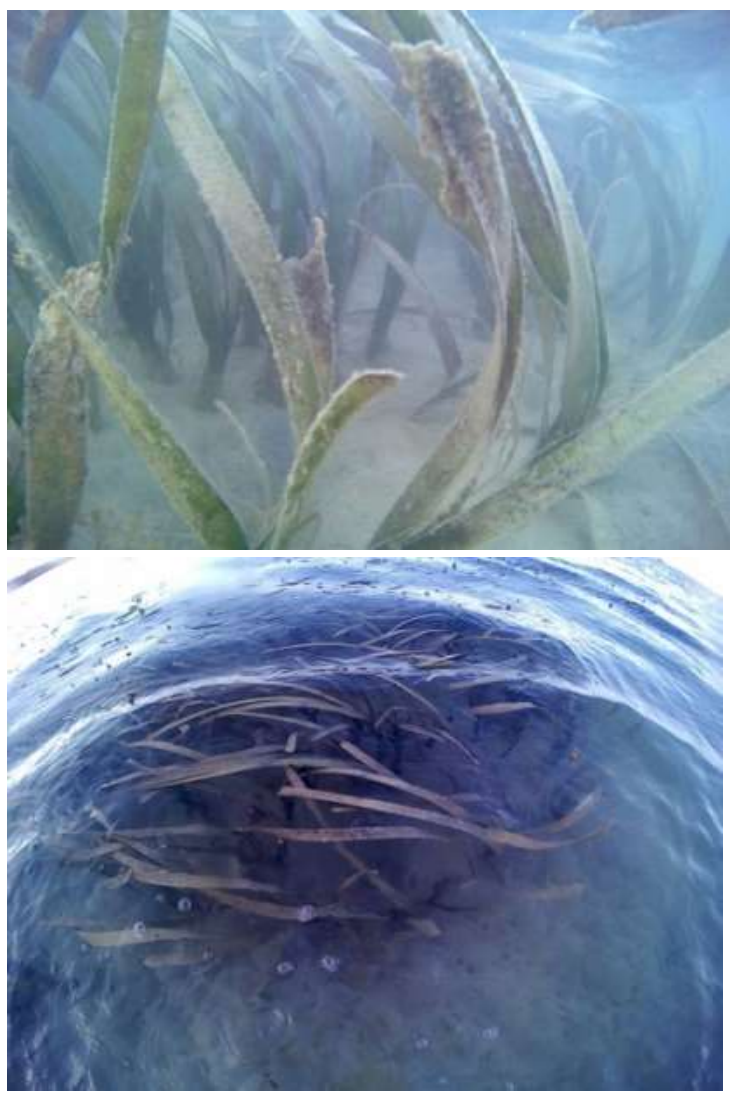

Gambar 1. Padang Lamun di Kepulauan Karimunjawa (Sumber: Andina Febrasari)

\section{Batik Kreasi Baru}

Batik Tulis Padang Lamun memiliki potensi untuk dikembangkan menjadi produk batik dengan kualitas premium yang inovatif dan memiliki nilai kebaharuan. Batik Tulis Padang Lamun sebagai gagasan memberikan kemungkinan sebagai produk baru yang berani menerobos batasan-batasan tanpa meninggalkan semangat batik tradisonal.

Berkembangnya batik kreasi baru saat ini memberikan peluang bagi Batik Tulis Padang Lamun untuk bersaing dengan produk lain, ragam hias yang baku mengalami modifikasi atau diganti dengan aneka corak baru yang lebih bebas. Demikian pula paduan warna yang mendobrak susunan warna tradisional. Selain itu, meskipun batik kreasi baru ini memiliki susunan motif tradisional, dalam penggunaannya lebih fleksibel dikarenakan bentuk pakaian maupun 
motifnya sudah tidak terikat dengan ketentuan pemakaian batik pakem (Darmaputri, 2015: 55).

Berbagai upaya untuk melestarikan batik yang disesuaikan dengan perkembangan selera pasar telah berlangsung sejak lama. Upaya-upaya ini antara lain dengan mengolah dan memanfaatkan teknik dan bahan yang ada. Teknik tradisional dikembangkan dengan inovasi baru demi menciptakan visual batik yang baru pula.

\section{Perkembangan Selendang}

Bersamaan dengan berkembangnya batik, selendang awalnya dikenal sebagai kain panjang tipis yang dipakai untuk keperluan khusus oleh wanita, yang umumnya dipakai sebagai pelengkap busana tradisional wanita Jawa. Kain ini dikenakan pada bahu dan dapat pula digunakan untuk menggendong bayi atau membawa keperluan ke pasar. Selendang juga berarti selembar kain hiasan yang dipakai melintang dari pundak ke pinggang atau menyelempang (Jasper, 1996: 95).

Ukuran selendang sama dengan kemben, namun fungsinya lebih beragam. Selendang gendongan yang digunakan di dalam keraton berukuran sama dengan kain panjang, yakni panjang lebih kurang $260 \mathrm{~cm}$ dan lebar lebih kurang $110 \mathrm{~cm}$ (Doellah, 2002: 22). Kedua ujung selendang diberi pola hiasan seperti yang ada pada kepala sarung. Selain itu, pada sisi terpanjang selendang terdapat pola hiasan yang disebut dengan corak pinggiran yang hadir dalam aneka ragam bentuk, mulai dari yang amat sederhana seperti bentuk-bentuk geometris segitiga (untu walang) pada selendang (Anas, 1997: $50)$.

Kini selendang muncul dengan berbagai macam bentuk dan ukuran serta berkembangnya beberapa motif yang lebih bervariasi (Sunarno, 2015: 54). Selain fungsinya sebagai pelengkap busana juga berfungsi sebagai nilai tambah keindahan bagi pemakainya. Eksistensi selendang sebagai bagian dari busana nasional yang tidak lekang oleh waktu, membawa selendang tetap digemari. Beberapa merek produk lokal bermunculan dengan membawa selendang sebagai salah satu produknya.

Penggunaan selendang saat ini, individu dapat mengatur penataan gaya agar sesuai dengan karakter masing-masing. Produk selendang batik yang sederhana dan tidak rumit, serta dapat dikombinasikan dengan pakaian lainnya. Batik dapat digunakan sebagai teknik, sedangkan untuk motif selendang dapat disesuaikan dengan perkembangan zaman.

\section{Metode Perancangan}

\section{a. Pendekatan Perancangan}

Pembahasan Batik Tulis Padang Lamun ini menggunakan pendekatan desain yang terdiri atas: (a) Proses Eksplorasi (exploration process), proses analisis bersifat pendalaman, penelusuran, penggali atas sejumlah hal; (b) Proses Ekstraksi (extraction process), proses analisis yang bersifat rangkuman, ekstraksi, dan pembuatan kesimpulan atas sejumlah hal; (c) Titik Terminasi, suatu titik yang mewakili kondisi awal saat mau memulai suatu kegiatan. Bentuk kegiatan pada titik terminasi berupa kegiatan perencanaan kegiatan, evaluasi, melihat kembali, dan presentasi. Tiga tahapan proses desain tersebut kemudian dijabarkan dalam empat langkah operasional, yakni: (a) proses analisis desain dan penetapan target perencanaan; (b) proses analisis aspek desain dan penyusunan konsep desain; (c) proses penjabaran konsep dan pembuatan desain (visualisasi); (d) proses tes produk (Palgunadi, 2007: 288). 


\section{b. Analisis Permasalahan}

Berdasarkan fokus permasalahan, ada beberapa permasalahan yang muncul dalam proyek perancangan ini. Pertama, pemahaman yang mendalam dan pencarian data terkait dengan keunikan Padang Lamun sebagai sumber ide, perkembangan motif batik kreasi baru komparasi untuk batik selendang sutra, dan pertimbangan batik sebagai produk premium. Kedua, permasalahan visualisasi, mengolah visual Padang Lamun menjadi motif batik. Ketiga, realisasi dalam teknik batik dan penentuan jenis bahan sutra yang digunakan untuk mendukung efek visual sesuai dengan karakter visual Padang Lamun dan fungsinya sebagai selendang.

\section{c. Strategi Pemecahan Masalah}

Mengacu pada analisis permasalahan di atas dapat disusun beberapa strategi yang dilakukan untuk menyelesaikan permasalahan tersebut. Pertama, langkah awal perancangan ini mengumpulkan data hasil wawancara, hasil observasi, dan literatur berkaitan dengan Padang Lamun, perkembangan motif batik kreasi baru, dan pertimbangan batik sebagai produk premium. Pengumpulan data tersebut bertujuan untuk mengetahui karakteristik Padang Lamun pada pengolahan visual motif batik untuk selendang sutra. Hal ini diperlukan untuk memperkuat perancangan ini. Kedua, mengolah visual dari Padang Lamun menggunakan beberapa alternatif gaya dengan lebih condong pengolahan bidang atau blocking dan mengurangi detail untuk memunculkan efek bayangan atau pertemuan warna. Tentu dengan mempertimbangkan unsur estetis dengan tetap mempertahankan keunikan dari visual Padang Lamun. Ketiga, melakukan studi produksi di Studio Batik "Brahma Tirta Sari" Yogyakarta yang diawali dengan proses uji coba teknik batik Lorodan pada kain sutra yang kemudian dianalisis sebagai hasil temuan. Studi produksi dilakukan dengan tujuan untuk mengurangi kemungkinan kegagalan pada proses perancangan dan proses produksi.

\section{Hasil Uji Coba Teknik dan Bahan}

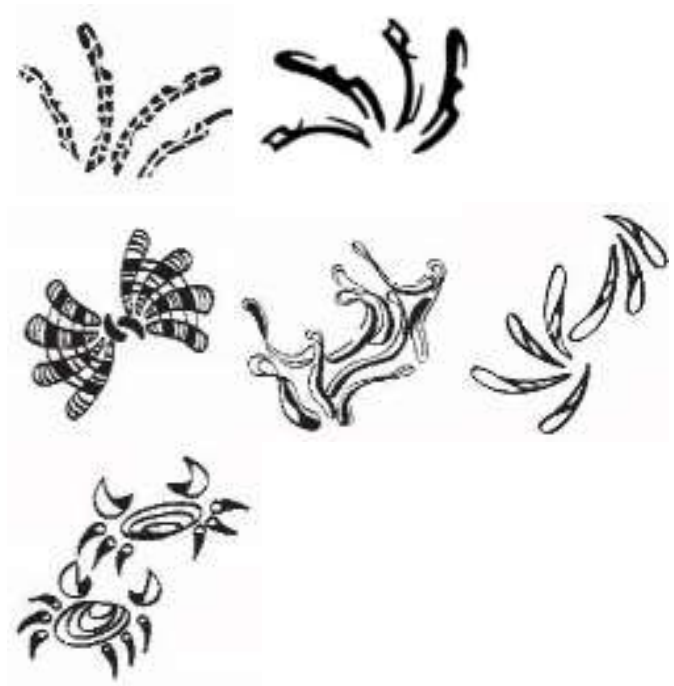

Gambar 2. Pengolahan Visual Padang Lamun dan Biota dengan Gaya Deformasi (Sumber: Andina Febrasari)

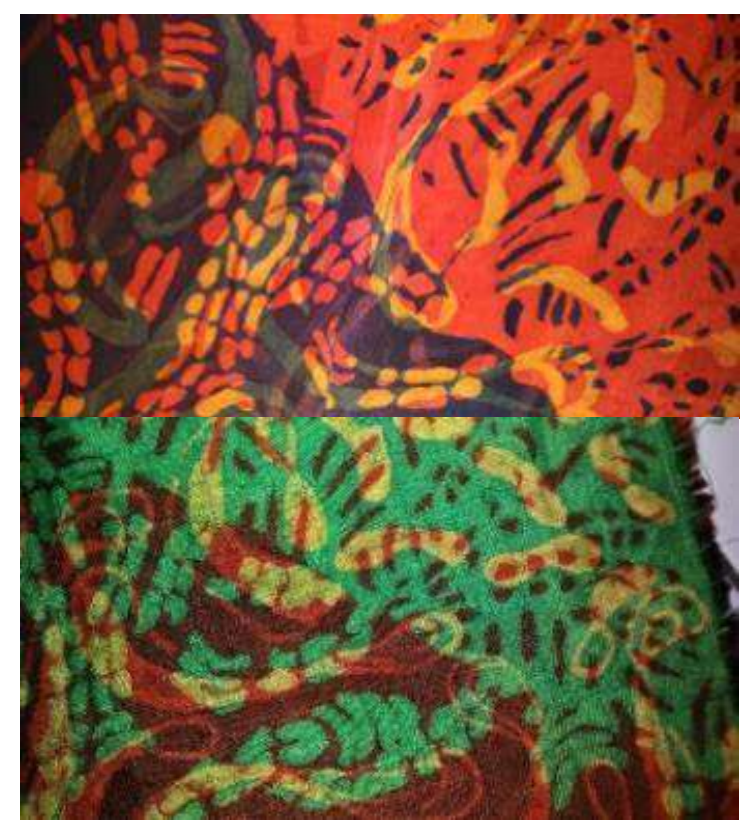




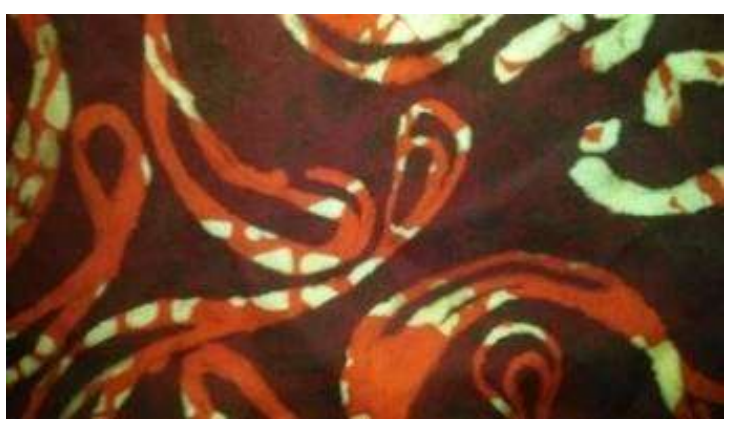

Gambar 3. Hasil Uji Coba Teknik Batik Lorodan pada Bahan Sutra

(Sumber: Andina Febrasari)

Berdasarkan uji coba teknik yang dilakukan, pada perancangan ini mengunakan teknik lorodan, yaitu dengan tiga kali pewarnaan, dua kali proses nyating, dan dua kali proseslorod. Bahan yang digunakan yaitu tiga jenis bahan sutra antara lain sutra mengilap tenun mesin, sutra tekstur kortak tenun bukan mesin, dan sutra crape. Alasan penggunaan ketiga bahan ini dikarenakan sutra satin memiliki sifat yang lembut, jatuh, dan permukaan yang mengilap, sehingga dapat mendukung fungsi selendang dan visual Padang Lamun. Bahan sutra tenun bukan mesin dipilih karena bahan ini mampu menyerap bahan pewarna dengan baik, sehingga dapat menghasilkan visual yang menarik. Jenis sutra Crape juga dipilih dikarenakan memberikan variasi tekstur yang berbeda, menyerap bahan pewarna dengan baik, dan sifatnya yang jatuh, dan mendukung fungsi selendang.

\section{Konsep Perancangan}

Serangkaian uji coba dan studi telah dilakukan. Koleksi ini mengambil tema Lamun Ombak dengan fokus perancangan mengolah visual Padang Lamun sebagai sumber ide. Padang Lamun menarik untuk diolah dari segi bentuk yang didominasi oleh daun pipih dan panjang seperti pita. Hidup bergerombol, daun yang menjuntai, digerakkan oleh gelombang laut menghasilkan puntiran, menumpuk, dan saling menjerat, sehingga memperlihatkan ilusi gerakan dan kedalaman. Visual ini juga didukung dengan tempat hidup Padang Lamun ini di daerah perairan dangkal dengan akar yang menjalar di pasir dan daun terbenam di dalam air, sehingga menghasilkan efek bayangan air ketika terkena cahaya pagi hari maupun sore hari.

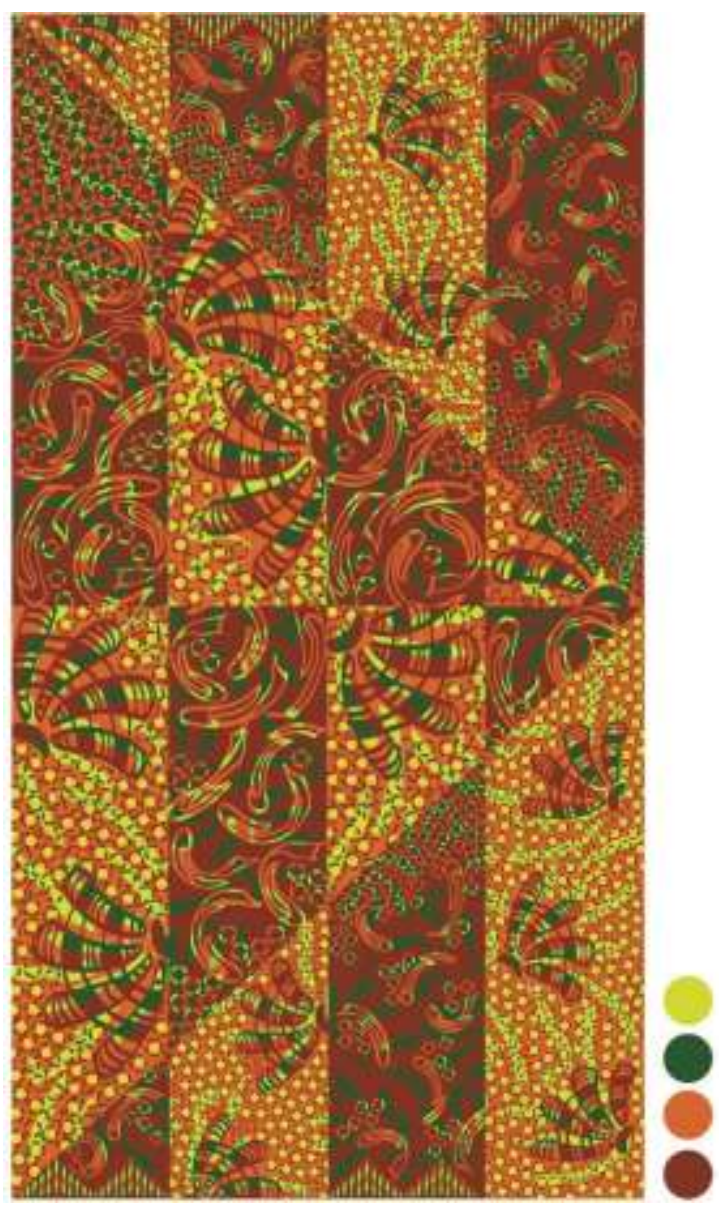

Gambar 4. Batik Pagi Sore

Visual Padang Lamun diolah dengan gaya deformasi dan menghasilkan efek ilusi untuk memberikan sensasi visual baru dalam batik motif flora. Warna desain cenderung menggunakan

warna kontras merah, oranye hingga ke kuning, hijau, dan biru. Warna-warna tersebut mewakili warna pasir, air laut, Padang Lamun, dan menggambarkan keadaan air ketika terkena cahaya matahari ketika sore hari. Selain itu, merah memberikan kesan hangat, kuning memberikan kesan mewah, dan biru memberikan kesan tenang. Komposisi pembagian warna dan motif mirip dengan batik Pagi Sore dengan bidang-bidang geometri untuk memberikan variasi antara desain satu dengan yang lainnya. 
Rancangan ini berhasil memvisualisaskan enam desain selendang dan tiga di antaranya diwujudkan menjadi produk. Desain motif ini diwujudkan pada selendang sutra dengan variasi ukuran $80 \mathrm{~cm} \times 150 \mathrm{~cm}$ dan $80 \mathrm{~cm} \times 200 \mathrm{~cm}$. Produk ini diarahkan pada produk premium untuk konsumen wanita usia 25-35 tahun.

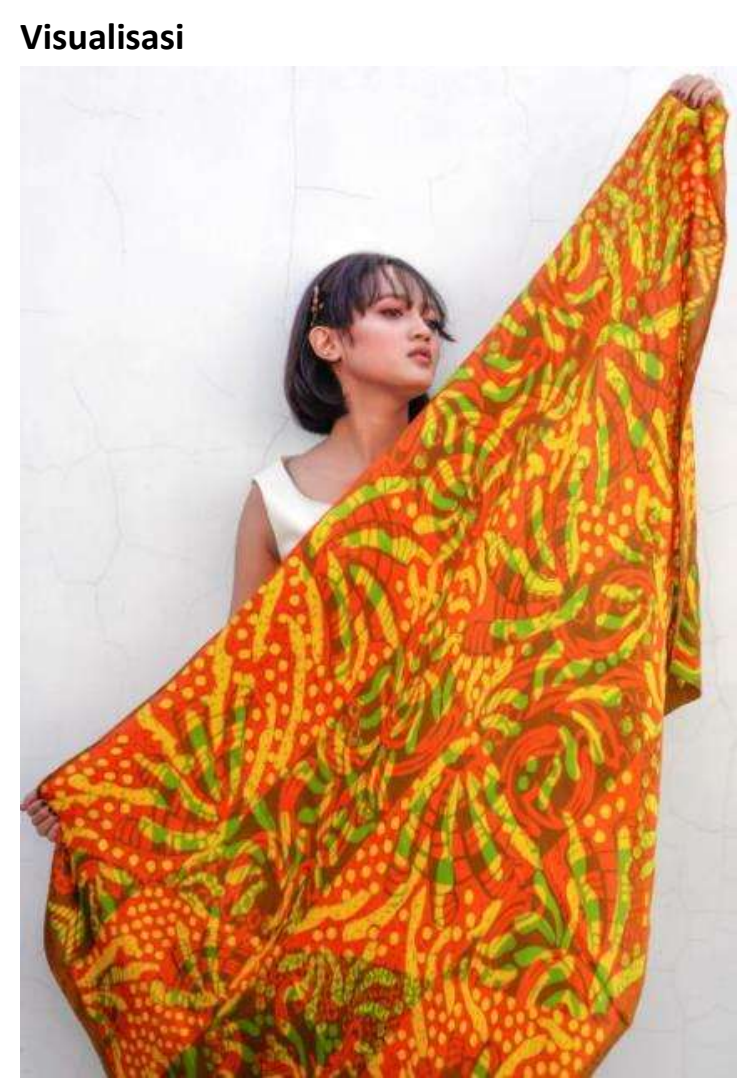

Gambar 5. Produk "Kerang Lamun" (Sumber: Andina Febrasari)

Desain pertama berjudul "Kerang Lamun" menggambarkan hubungan Padang Lamun dengan kerang laut. Kerang laut yang tinggal di dalam Padang Lamun pada umumya berlindung di sekitar daun untuk menghindari predator dan koyakan gelombang laut.
Desain ini diarahkan ke dalam pengolahan desain panel dengan ukuran 80 $\mathrm{cm} \times 150 \mathrm{~cm}$. Visual yang diolah yaitu Padang Lamun jenis Thalassia hemprichii dan kerang laut dengan gaya deformasi mengandalkan bidang dan garis berbidang atau blocking. Pembagian warna dengan bidang geometri membentuk segitiga. Warna yang digunakan yaitu warna-warna kontras, seperti warna kuning, hijau, merah, dan orange. Warna baru muncul dengan intensitas warna yang berbeda akibat pertemuan dua warna pada teknik batik Lorodan

Bahan yang digunakan yaitu kain sutra tenun mesin, dikarenakan sifat kain yang jatuh, halus, dan mengilap. Selendang yang dihasilkan dapat dipadukan dengan busana semi-formal hingga formal untuk mendukung kesan penampilan yang tampak elegan.

Desain kedua fokus pada pengolahan motif Padang Lamun jenis Thalassia hemprichii dengan judul "Jelamun." Nama "Jelamun" ini merupakan sebutan yang diberikan oleh warga Karimunjawa untuk Padang Lamun. Desain diarahkan ke dalam pengolahan desain panel ukuran $80 \mathrm{~cm}$ x150 $\mathrm{cm}$. Puntiran daun Padang Lamun ini saat tersentuh arus laut tampak gemulai dan luwes. Komposisi warna dan motif desain ini dibagi dalam bidang geometri membentuk segitiga pada arah diagonal.

Warna yang digunakan merupakan warna-warna kontras sebagai pusat perhatian seperti warna kuning, merah, coklat, dan hijau. Bahan yang digunakan yaitu kain sutra tekstur kotak tenun bukan mesin, hal ini dikarenakan sifat kain yang tidak terlalu kaku ketika sudah diproses, halus, dan daya serap warna baik. Paduan warna merah, hijau, dan kuning serta visual motif yang dinamis memunculkan kesan hangat dan energik. 
Selendang ini tepat untuk kosumen yang menggemari warna yang berani namun tetap terkesan anggun dan menarik.
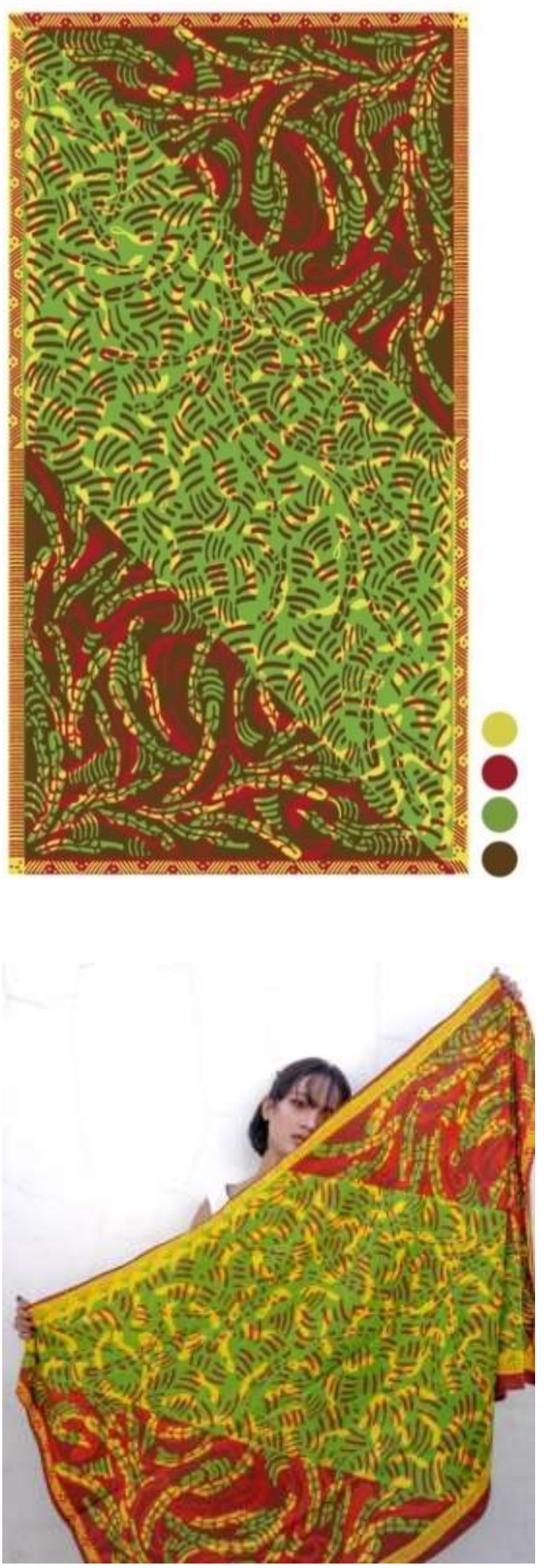

Gambar 6. Produk "Jelamun”
(Sumber: Andina Febrasari)

Desain ketiga berjudul "Lamun Juvenile" terinspirasi interaksi ikan pada tahap juvenile dengan Padang Lamun jenis Thalassia hemprichii. Padang Lamun relatif aman untuk masa hidup ikan pada tahap juvenile karena dapat menjadi tempat berlindung dari serangan predator. Desain ini diarahkan ke dalam pengolahan desain panel ukuran $80 \mathrm{~cm} \times 200 \mathrm{~cm}$.
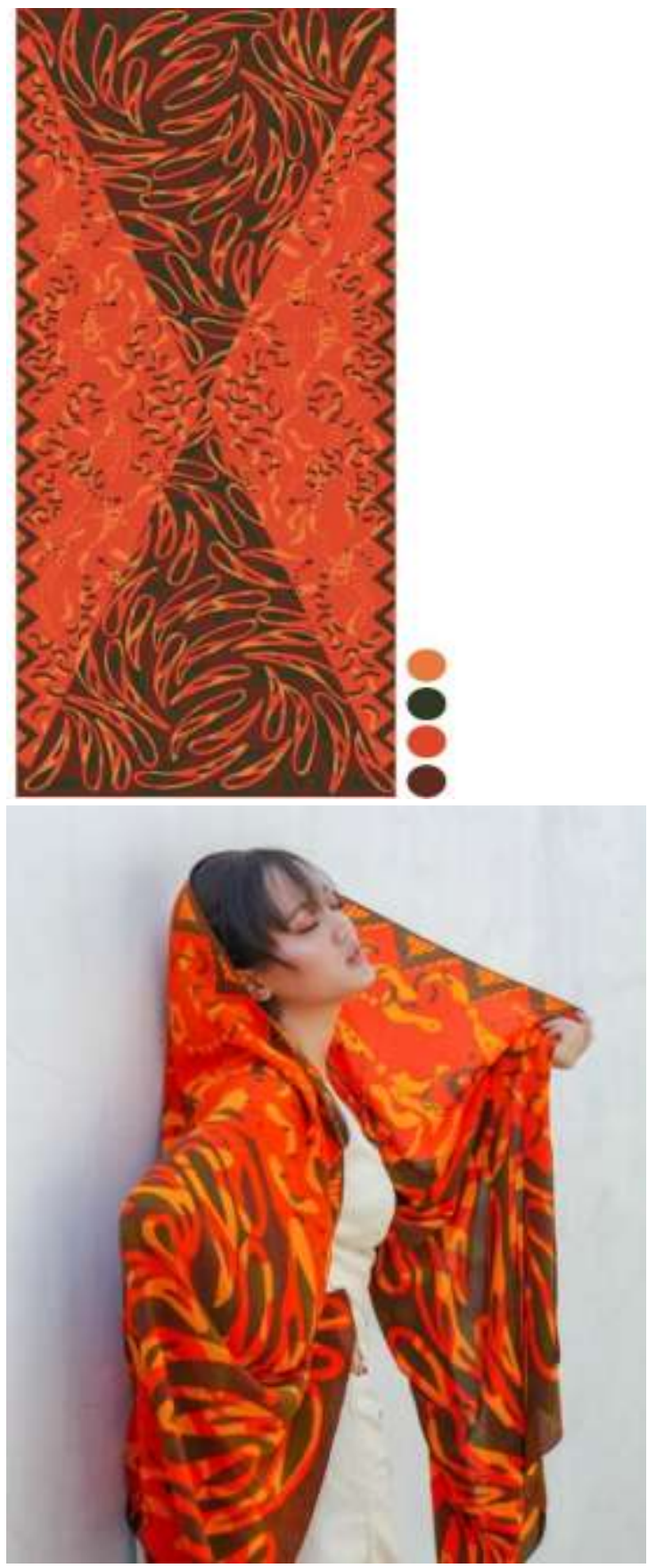

Gambar 7. Produk "Lamun Juvenile" 
(Sumber: Andina Febrasari)

Visual Thalassia hemprichii dan ikan Juvenile diolah dengan gaya deformasi berikut dengan tritik. Desain ini didominasi oleh warna oranye yang menggambarkan keadaan Padang Lamun ketika sore hari. Bahan yang digunakan yaitu kain sutra crape, dikarenakan sifat kain yang lembut, sedikit mengilap, jatuh, sedikit bertekstur, dan daya serap warna yang baik. Selendang yang dihasilkan cocok untuk memunculkan nuansa klasik namun tetap dinamis pada paduan busana penggunanya.

\section{PENUTUP}

Hasil pembahasan dari tulisan ini dapat ditarik kesimpulan sebagai berikut:

Pertama, potensi keunikan estetis Padang Lamun terletak pada visual ilusi gerak, bayangan, dan dimensi. Visual Padang Lamun diolah dengan arahan batik kreasi baru dengan gaya deformasi. Gaya tersebut menjadi salah satu pembeda dengan produk yang ada di pasar sekaligus sebagai inovasi pengolahan visual tanpa harus menghilangkan karakter dan bentuk Padang Lamun. Batik Padang Lamun diterapkan dalam produk selendang sutra yang terlihat kekinian namun tetap memunculkan motif khas selendang batik tradisi, yaitu isen-isen dan motif pinggiran. Komposisi motif dan warna mengambil konsep menyerupai batik pagi sore yang dikreasikan dengan latar geometri.

Kedua, teknik yang digunakan adalah teknik batik tulis Lorodan untuk mendukung visual yang dihasilkan serta memberikan keberimbangan sebagai produk premium. Batik tulis Lorodan memunculkan goresan yang khas dan efek visual Padang Lamun terkesan di dalam air. Teknik ini mampu menghasilkan warna tambahan akibat adanya pertemuan warna. Teknik ini dilakukan dengan dua kali proses nyanting, tiga kali proses pewarnaan, dan dua kali proses lorod untuk menghasilkan visual dengan kesan adanya bayangan, ilusi gerakan, dan berlapislapis.

\section{DAFTAR PUSTAKA}

Anas, Biranul. 1997. Indonesia Indah "Batik". Jakarta: Yayasan Harapan Kita, Perum Percetakan Negara Republik Indonesia.

Darmaputri, Gabriela Lordy. 2015. "Representasi Identitas Kultural dalam Simbol-simbol Tradisional dan Kontemporer". Vol.4 No.2.

Doellah, Santosa. 2002. Batik: Pengaruh Zaman dan Lingkungan. Surakarta: Danar Hadi.

Jasper, J. 1996. Seni Batik (De Batik-kunst De Inlandsche Kunstnijyerheid in Nederlandsch Indie). Japan: Tim Peneliti Batik Indonesia.

Kawaroe, M. 2009. "Perspektif Lamun sebagai Blue Carbon Sink di Laut." Departemen Ilmu dan Teknologi Kelautan Fakultas Perikanan dan IImu Kelautan IPB, Bogor.

Kuslani, Henra. 2014. “Komposisi Jenis Lamun di Pulau Menjangan Besar, Kepulauan Karimunjawa, Jawa Tengah." Laporan penelitian, Balai Penelitian Pemulihan dan Konservasi Sumber Daya Ikan, Jatiluhur.

Nugraha, Y. 2015. "Teknik Identifikasi Lamun (Seagrass) di Kawasan Pulau Parang, Karimunjawa Kabupaten Jepara". Th. XIII. No. 2.

Nybakken, J. 1992. Biologi Laut: Suatu Pendekatan Ekologis. Jakarta: Gramedia.

Palgunadi, B. 2007. Desain Produk. Bandung: Institut Teknologi Bandung. 
Sunarno, N. 2015. "Upacara Adat Pengantin Gaya Yogyakarta sebagai Inspirasi dalam Penciptaan Motif Batik pada Selendang." Tugas Akhir Universitas Negeri Yogyakarta.

Susanto, S.K. Sewan. 1980. Seni Kerajinan Batik Indonesia. Yogyakarta: Balai Penelitian Batik dan Kerajinan. 